\title{
Wetting Properties of Seven Phosphonium Cation-Based lonic Liquids
}

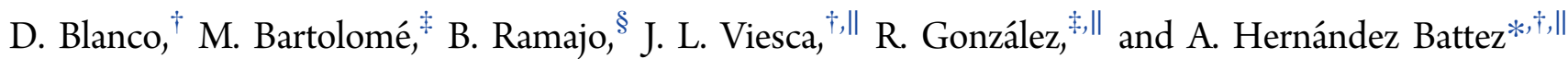 \\ ${ }^{\dagger}$ Department of Construction and Manufacturing Engineering, University of Oviedo, Asturias, Spain \\ ${ }^{\ddagger}$ Department of Marine Science and Technology, University of Oviedo, Asturias, Spain \\ ${ }^{\S}$ Department of Physical and Analytical Chemistry, University of Oviedo, Asturias, Spain \\ "Department of Design and Engineering, Bournemouth University, Poole BH12 5BB, United Kingdom
}

\section{Supporting Information}

ABSTRACT: This paper studies the wetting properties of seven phosphonium cation-based ionic liquids: trihexyltetradecylphosphonium bis(2,4,4-trimethylpentyl) phosphinate $\left[\mathrm{P}_{66614}\right]\left[(\mathrm{iC} 8)_{2} \mathrm{PO}_{2}\right]$, trihexyltetradecylphosphonium bis $(2-$ ethylhexyl)phosphate $\left[\mathrm{P}_{66614}\right][\mathrm{BEHP}]$, trihexyltetradecylphosphonium bis(trifluoromethylsulfonyl) imide $\left[\mathrm{P}_{66614}\right]\left[\mathrm{NTf}_{2}\right]$, tributyltetradecylphosphonium dodecylbenzenesulfonate $\left[\mathrm{P}_{44414}\right][\mathrm{DBS}]$, tributylethylphosphonium diethylphosphate $\left[\mathrm{P}_{4442}\right][\mathrm{DEP}]$, trihexyltetradecylphosphonium dicyanamide $\left[\mathrm{P}_{66614}\right][\mathrm{DCA}]$, and trihexyltetradecylphosphonium chloride $\left[\mathrm{P}_{66614}\right][\mathrm{Cl}]$. The surface tension was analyzed using the Gibbs free energy in a temperature range of 293-353 K, obtaining the expected linear decrease with temperature rise. The contact angle was measured on four different surfaces (AISI 52100 steel, $\mathrm{CrN}$, TiN, and $\mathrm{ZrN}$ ) and all liquids with high surface tensions interacting with hydrophobic systems displayed high contact angles as expected. The polarity fraction (PF) and the spreading parameter (SP) were estimated to complete and improve the wetting characterization of these ionic liquids, finding TiN- $\left[\mathrm{P}_{66614}\right][\mathrm{BEHP}]$ and TiN- $\left[\mathrm{P}_{66614}\right]\left[(\mathrm{iC} 8)_{2} \mathrm{PO}_{2}\right]$ as the most favorable surface-ionic liquid combinations from a wetting point of view.

\section{INTRODUCTION}

Ionic liquids (ILs) are attracting recent research interest as potential candidates for discovering clean technologies ${ }^{1-3}$ due to their unique properties such as low melting temperature, nonflammable behavior, high thermal stability, near-zero vapor pressure, wide electrochemical window, large liquid range, high ionic conductivity, and a highly adjustable solvating capacity for both polar and nonpolar compounds. Evaluating the physicochemical properties of these molten salts is essential to guarantee the use of such compounds in a broad range of applications. $^{4-7}$ An accurate design of industrial processes based on ILs can only be achieved when their physicochemical properties are well-known. Therefore, it is important to measure these properties in order to improve their characterization, not only for designing but also for developing correlations either between these properties or with performance parameters. ${ }^{8}$

One of the main advantages of working with ILs is the possibility of easily adapting their properties with small variations in the chemical composition, thus having a huge potential for engineering applications. ${ }^{2}$ This fact may be used as a tool for self-tuning the ILs with multiple and useful application possibilities by changing physicochemical properties, such as density, melting point, viscosity, conductivity, or surface tension. ${ }^{9}$ For instance, water miscibility of ILs is usually controlled by the anion, although the cation can also affect the hydrophobicity of the substance. Moreover, increasing either the size of the anion or the alkyl side chains of the cation leads to a decrease in polarity due to the spreading of negative charge. ${ }^{10}$ Therefore, a study of the relationship between structure and physicochemical properties could enable designing ILs with tailored capabilities. ${ }^{1}$

From the lubrication point of view, understanding the tendency of a liquid to spread on a solid surface is a very important factor affecting the performance of the lubricant. $^{11-13}$ Furthermore, thin hard physical vapor-deposited (PVD) coatings are also frequently used in a number of engineering applications. ${ }^{12-20}$ Measuring surface tension and contact angle are a good way to evaluate wetting ability. ${ }^{21}$ The surface tension (eq 1) can be divided as a sum of independent contributions named dispersive (d) and nondispersive (nd), with only dispersive interactions (determined using the geometric mean rule) occurring across the interface. ${ }^{22}$ There-

Received: February 29, 2016

Revised: July 18, 2016

Accepted: August 23, 2016 
fore, the work of adhesion $\left(W_{\mathrm{SL}}\right)$ as depicted in eqs 2 and 3 can relate these dispersive interactions with the solid-liquid interfacial tension $\left(\gamma_{\mathrm{SL}}\right)$, linked with the contact angle $(\theta)$ through the Young equation (eq 4), as shown in Figure 1,

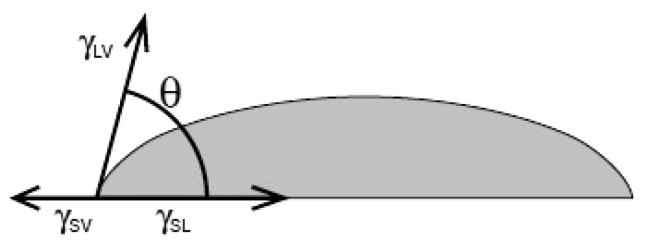

Figure 1. Relationship between surface tensions and contact angle $(\theta)$.

where total surface energy $\left(\gamma_{S V}\right)$ and interfacial tension liquidvapor $\left(\gamma_{\mathrm{LV}}\right)$ are usually expressed as $\gamma_{\mathrm{S}}$ and $\gamma_{\mathrm{L}}$, respectively.

$$
\begin{aligned}
& \gamma=\gamma^{\mathrm{d}}+\gamma^{\mathrm{nd}} \\
& W_{\mathrm{SL}}=2 \sqrt{\left(\gamma_{\mathrm{S}}^{\mathrm{d}} \cdot \gamma_{\mathrm{L}}^{\mathrm{d}}\right)} \\
& \gamma_{\mathrm{SL}}=\gamma_{\mathrm{S}}+\gamma_{\mathrm{L}}-W_{\mathrm{SL}} \\
& \gamma_{\mathrm{SL}}=\gamma_{\mathrm{S}}-\gamma_{\mathrm{L}} \cos \theta
\end{aligned}
$$

In order to obtain a unique contact angle for each threephase system using this equation, it was assumed that the surface is homogeneous and flat so the surface tension of the interfaces remains constant. ${ }^{9}$ Merging the above eqs (eqs 1-4), it is possible to correlate the most important wetting properties: contact angle and surface tension. This eq (eq 5) is valid when both phases are nonpolar and may be a good estimate when at least one of them is nonpolar.

$$
\gamma_{\mathrm{L}} \cdot(1+\cos \theta)=2 \sqrt{\gamma_{\mathrm{S}}^{\mathrm{d}} \gamma_{\mathrm{L}}^{\mathrm{d}}}
$$

In addition to the contact angle and the surface tension, wettability can also be evaluated using the spreading parameter (SP), ${ }^{12,13,20,23}$ which represents the difference between the work of adhesion defined in eq 2 and the work of cohesion $\left(W_{\mathrm{C}}\right)$ within the liquid (eqs 6-7), defined as the work per unit area required to isothermally split a homogeneous liquid. ${ }^{2}$

$$
\begin{aligned}
& \mathrm{SP}=W_{\mathrm{SL}}-W_{\mathrm{C}} \\
& W_{\mathrm{C}}=2 \gamma_{\mathrm{L}}
\end{aligned}
$$

From eqs 4 and 5, a new eq (eq 8) that enables estimating the spreading properties using data from both liquid and surface was derived by Kalin and Polajnar. ${ }^{12,13,20}$

$$
\mathrm{SP}=2 \sqrt{\gamma_{\mathrm{S}}^{\mathrm{d}} \gamma_{\mathrm{L}}^{\mathrm{d}}}+2 \sqrt{\gamma_{\mathrm{S}}^{\text {nd }} \gamma_{\mathrm{L}}^{\text {nd }}}-2 \gamma_{\mathrm{L}}
$$

The study of wetting properties for ILs (with the exception of imidazolium cation-based ILs) has been poorly investigated, ${ }^{1,4,7-10,21,24-46}$ even though the value of understanding and controlling wetting has become a key factor in many engineering applications, including lubrication. Due to its growing commercial availability and its good performance as a lubricant additive, ${ }^{47-51}$ wetting properties such as contact angle, surface tension, SP, and PF of seven commercially available phosphonium cation-based ILs- $\left[\mathrm{P}_{66614}\right][\mathrm{BEHP}]$, $\left[\mathrm{P}_{66614}\right]\left[(\mathrm{iC} 8)_{2} \mathrm{PO}_{2}\right], \quad\left[\mathrm{P}_{66614}\right]\left[\mathrm{NTf}_{2}\right],\left[\mathrm{P}_{44414}\right][\mathrm{DBS}], \quad\left[\mathrm{P}_{4442}\right]$ $[\mathrm{DEP}],\left[\mathrm{P}_{66614}\right][\mathrm{DCA}]$, and $\left[\mathrm{P}_{66614}\right][\mathrm{Cl}]$-used as supplied were measured or estimated in order to ensure their feasibility in the field of lubrication.

\section{EXPERIMENTAL DETAILS}

2.1. ILs. In order to carry out this study, all ILs were selected from an available family of these substances, recently and widely used in a number of applications such as extraction solvents, chemical synthesis, electrolytes, corrosion protection and tribology. ${ }^{52}\left[\mathrm{P}_{66614}\right]\left[(\mathrm{iC} 8)_{2} \mathrm{PO}_{2}\right],\left[\mathrm{P}_{66614}\right][\mathrm{BEHP}],\left[\mathrm{P}_{66614}\right]$ $\left[\mathrm{NTf}_{2}\right],\left[\mathrm{P}_{44414}\right][\mathrm{DBS}],\left[\mathrm{P}_{4442}\right][\mathrm{DEP}]$ and $\left[\mathrm{P}_{66614}\right][\mathrm{DCA}]$ were provided by Ionic Liquid Technologies $\mathrm{GmbH}$ (Io-Li-Tec). In addition, $\left[\mathrm{P}_{66614}\right][\mathrm{DCA}]$ was provided by Sigma-Aldrich. Table 1 shows the chemical description of the ILs and Figure 2 depicts their chemical structure.

A Stabinger SVM3000 rotational Couette viscometer was used to measure viscosity and density (vibrating tube density meter incorporated) according to ASTM D7042 at atmospheric pressure from 10 to $100{ }^{\circ} \mathrm{C}$. The viscosity index (VI) was also automatically calculated ${ }^{5}$ by the software according to ASTM D2270-04. Experimental density results were quite consistent with those found in the literature. On the other hand, experimental viscosity results showed some differences with values reported in the literature (especially for $\left[\mathrm{P}_{4442}\right][\mathrm{DEP}]$ and $\left.\left[\mathrm{P}_{66614}\right][\mathrm{DCA}]\right)$, likely related to variations in purity values of the samples tested (Table 2).

2.2. Wetting Properties. In order to carry out a proper thermophysical characterization, several properties related to the wettability of the studied ILs were analyzed. Surface tension of the ILs was measured following Du Noüy's platinum ring method $^{55}$ using a KSV Sigma 700 tensiometer (KSV Instruments Ltd., Finland) in the temperature range $20-80{ }^{\circ} \mathrm{C}$. The reported values were the average of at least 10 different measurements at each temperature and the standard deviations

\begin{tabular}{|c|c|c|c|c|c|}
\hline IUPAC name & acronym & CAS no. & $\begin{array}{l}\text { purity } \\
(\%)\end{array}$ & $\begin{array}{l}\text { molecular } \\
\text { weight }\end{array}$ & empirical formula \\
\hline $\begin{array}{l}\text { Trihexyltetradecylphosphonium bis(2,4,4-trimethylpentyl) } \\
\text { phosphinate }\end{array}$ & {$\left[\mathrm{P}_{66614}\right]\left[(\mathrm{iC} 8)_{2} \mathrm{PO}_{2}\right]$} & $465527-59-7$ & 95 & 773.27 & $\mathrm{C}_{48} \mathrm{H}_{102} \mathrm{O}_{2} \mathrm{P}_{2}$ \\
\hline Trihexyltetradecylphosphonium bis(2-ethylhexyl)phosphate & {$\left[\mathrm{P}_{66614}\right][\mathrm{BEHP}]$} & $1092655-30-5$ & 98 & 805.29 & $\mathrm{C}_{48} \mathrm{H}_{102} \mathrm{O}_{4} \mathrm{P}_{2}$ \\
\hline Trihexyltetradecylphosphonium bis(trifluoromethylsulfonyl) imide & {$\left[\mathrm{P}_{66614}\right]\left[\mathrm{NTf}_{2}\right]$} & $460092-03-9$ & 98 & 764.01 & $\mathrm{C}_{34} \mathrm{H}_{68} \mathrm{~F}_{6} \mathrm{NO}_{4} \mathrm{PS}_{2}$ \\
\hline Tributyltetradecylphosphonium dodecylbenzenesulfonate & {$\left[\mathrm{P}_{44414}\right][\mathrm{DBS}]$} & & 95 & 725.18 & $\mathrm{C}_{44} \mathrm{H}_{85} \mathrm{O}_{3} \mathrm{PS}$ \\
\hline Tributylethylphosphonium Diethylphosphate & {$\left[\mathrm{P}_{4442}\right][\mathrm{DEP}]$} & $20445-94-7$ & 95 & 384.47 & $\mathrm{C}_{18} \mathrm{H}_{42} \mathrm{O}_{4} \mathrm{P}_{2}$ \\
\hline Trihexyltetradecylphosphonium dicyanamide & {$\left[\mathrm{P}_{66614}\right][\mathrm{DCA}]$} & $701921-71-3$ & 95 & 550.91 & $\mathrm{C}_{34} \mathrm{H}_{69} \mathrm{PN}_{3}$ \\
\hline Trihexyltetradecylphosphonium chloride & {$\left[\mathrm{P}_{66614}\right][\mathrm{Cl}]$} & $258864-54-9$ & 95 & 519.31 & $\mathrm{C}_{32} \mathrm{H}_{68} \mathrm{PCl}$ \\
\hline
\end{tabular}
were less than $0.04 \mathrm{~mJ} / \mathrm{m}^{2}$ degrees in each case.

According to the methodology described by Tadros et al., 56 contact angles of the ILs were calculated using sessile drops with a KSV CAM 200 goniometer equipped with a micrometer syringe. The drop expanded during the room temperature experiments in order to allow for measurement of dynamic

Table 1. Chemical Description of ILs Used in This Work 


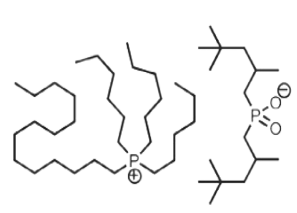

$\left[\mathrm{P}_{66614}\right]\left[(\mathrm{iC} 8)_{2} \mathrm{PO}_{2}\right]$

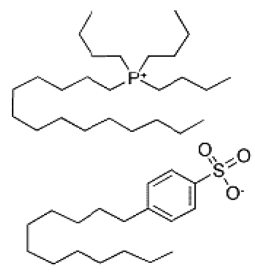

$\left[\mathrm{P}_{44414}\right][\mathrm{DBS}]$

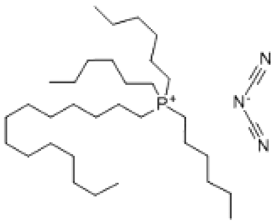

$\left[\mathrm{P}_{66614}\right][\mathrm{DCA}]$
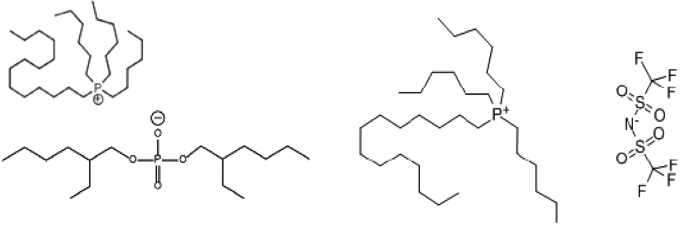

$\left[\mathrm{P}_{66614}\right][\mathrm{BEHP}]$

$\left[\mathrm{P}_{66614}\right]\left[\mathrm{NTf}_{2}\right]$

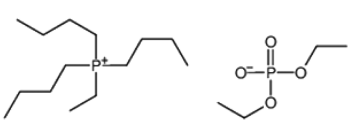

$\left[\mathrm{P}_{4442}\right][\mathrm{DEP}]$

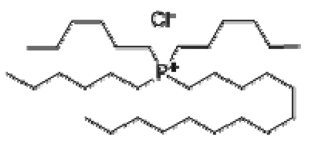

$\left[\mathrm{P}_{66614}\right][\mathrm{Cl}]$

Figure 2. Chemical structure of the ionic liquids.

Table 2. Comparison between Density and Viscosity Experimental Values (exp.) of the ILs versus Values (ref) Found in the Literature ${ }^{25,33,44,51,53,54}$

\begin{tabular}{|c|c|c|c|c|c|c|c|c|c|}
\hline \multirow[b]{4}{*}{ short name } & \multicolumn{8}{|c|}{ ionic liquids } & \multirow[b]{4}{*}{ VI } \\
\hline & \multirow{2}{*}{\multicolumn{2}{|c|}{$\frac{\text { density }}{\rho\left(\mathrm{g} / \mathrm{cm}^{3}\right) / 20{ }^{\circ} \mathrm{C}}$}} & \multicolumn{6}{|c|}{ viscosity } & \\
\hline & & & \multicolumn{2}{|c|}{$\nu(\mathrm{mPa} \cdot \mathrm{s}) / 25^{\circ} \mathrm{C}$} & \multicolumn{2}{|c|}{$\nu(\mathrm{mPa} \cdot \mathrm{s}) / 40{ }^{\circ} \mathrm{C}$} & \multicolumn{2}{|c|}{$\nu(\mathrm{mPa} \cdot \mathrm{s}) / 100^{\circ} \mathrm{C}$} & \\
\hline & exp. & ref & exp. & ref & exp. & ref & exp. & ref & \\
\hline$\left[\mathrm{P}_{66614}\right]\left[(\mathrm{iC} 8)_{2} \mathrm{PO}_{2}\right]$ & 0.8867 & $0.8877^{53}$ & 1064 & $1058^{53}$ & 462.5 & $447.95^{53}$ & 46.2 & $42.79^{53}$ & 169 \\
\hline$\left[\mathrm{P}_{66614}\right][\mathrm{BEHP}]$ & 0.9116 & $0.91^{51}$ & 1050 & $1031^{51}$ & 474.3 & $418.4^{51}$ & 50.8 & $49.2^{51}$ & 181 \\
\hline$\left[\mathrm{P}_{66614}\right]\left[\mathrm{NTf}_{2}\right]$ & 1.0711 & $1.070^{44}$ & 295.9 & $336.74^{44}$ & 130.4 & $151.85^{44}$ & 16.4 & & 140 \\
\hline$\left[\mathrm{P}_{44414}\right][\mathrm{DBS}]$ & 0.9554 & $0.9384^{25}$ & 4212 & & 1278 & & 56.5 & & 98 \\
\hline$\left[\mathrm{P}_{4442}\right][\mathrm{DEP}]$ & 1.0112 & $1.014^{33}$ & 454.8 & $316.8^{33}$ & 171.4 & $124.7^{33}$ & 14.2 & & 83 \\
\hline$\left[\mathrm{P}_{66614}\right][\mathrm{DCA}]$ & 0.9010 & $0.8989^{54}$ & 284.4 & $418.33^{54}$ & 131.6 & & 15.1 & & 117 \\
\hline$\left[\mathrm{P}_{66614}\right][\mathrm{Cl}]$ & 0.8921 & $0.8826^{25}$ & 1875.9 & & 631.3 & & 38.1 & & 97 \\
\hline
\end{tabular}

advancing contact angles $\left(\theta_{\mathrm{A}}\right)$, recorded from digital images taken at a fixed time interval (first 8 images were taken every half second and the following 30 every $6 \mathrm{~s}$ ). The advancing contact angle was measured on both sides of the drop, and this methodology is usually performed to characterize solid surfaces. The reference plane that contains the three-phase line (Figure 1 ) is located at the interphase, so the contact angle $\theta$ is calculated as an optimization parameter, using a Laplacian curve to fit the drop image from the contact point to a certain height of the drop. ${ }^{57}$ The substrates used for these tests were: AISI 52100 steel discs (machined from annealed rod) with a hardness of 190-210 $\mathrm{HV}_{30}$ and a surface finish ( $\mathrm{Ra}$ ) of 0.0489 $\mu \mathrm{m}$ and 3 alloy nitride coatings ( $\mathrm{TiN}, \mathrm{CrN}, \mathrm{ZrN}$ ) obtained by physical vapor deposition (PVD) on the same steel discs. Surface finish $(\mathrm{Ra})$ was measured after the deposition process reached the following values: $0.0477 \mu \mathrm{m}$ for TiN, $0.0474 \mu \mathrm{m}$ for $\mathrm{CrN}$, and $0.0487 \mu \mathrm{m}$ for $\mathrm{ZrN}$. All substrates used were cleaned before the wetting tests with acetone in an ultrasonic bath for 2 min and dried with air. The reported contact angles were the average of at least ten different points when the steady state was reached and the standard deviations were less than 0.7 degrees in each case.

2.3. Error Analysis. All experimental equipment used in this research was calibrated before carrying out each experimental series. After the tests, no appreciable deviation compared to standard substances was found; therefore, the inherent error was negligible. Moreover, all experimental data reported were the result of several runs in the same experimental conditions, adding the uncertainty as standard deviation to the average value and thus quantifying the magnitude of random error.

The propagation of individual uncertainties associated with the measured variables (throughout the different equations used) was determined from the law of propagation of uncertainty, with the general equation shown in eq 9. The 
Table 3. Experimental Surface Tension Data for Pure Ionic Liquids

\begin{tabular}{|c|c|c|c|c|c|}
\hline \multicolumn{2}{|c|}{$\left[\mathrm{P}_{66614}\right]\left[(\mathrm{iC} 8)_{2} \mathrm{PO}_{2}\right]$} & \multicolumn{2}{|c|}{$\left[\mathrm{P}_{66614}\right][\mathrm{BEHP}]$} & \multicolumn{2}{|c|}{$\left[\mathrm{P}_{66614}\right]\left[\mathrm{NTf}_{2}\right]$} \\
\hline$T \pm \sigma\left({ }^{\circ} \mathrm{C}\right)$ & $\gamma \pm \sigma\left(\mathrm{mJ} / \mathrm{m}^{2}\right)$ & $T \pm \sigma\left({ }^{\circ} \mathrm{C}\right)$ & $\gamma \pm \sigma\left(\mathrm{mJ} / \mathrm{m}^{2}\right)$ & $T \pm \sigma\left({ }^{\circ} \mathrm{C}\right)$ & $\gamma \pm \sigma\left(\mathrm{mJ} / \mathrm{m}^{2}\right)$ \\
\hline $21.105 \pm 0.060$ & $28.289 \pm 0.006$ & $20.431 \pm 0.064$ & $27.525 \pm 0.007$ & $21.181 \pm 0.128$ & $29.327 \pm 0.009$ \\
\hline $29.916 \pm 0.114$ & $27.345 \pm 0.028$ & $30.978 \pm 0.518$ & $27.021 \pm 0.015$ & $30.799 \pm 0.266$ & $28.607 \pm 0.013$ \\
\hline $40.012 \pm 0.096$ & $26.553 \pm 0.009$ & $40.302 \pm 0.419$ & $26.353 \pm 0.018$ & $39.698 \pm 0.049$ & $27.969 \pm 0.029$ \\
\hline $48.557 \pm 0.342$ & $25.879 \pm 0.017$ & $50.209 \pm 0.261$ & $25.640 \pm 0.036$ & $50.363 \pm 0.337$ & $27.154 \pm 0.026$ \\
\hline $60.426 \pm 0.600$ & $24.933 \pm 0.067$ & $59.451 \pm 0.163$ & $24.945 \pm 0.016$ & $59.631 \pm 0.115$ & $26.486 \pm 0.022$ \\
\hline $69.983 \pm 0.591$ & $24.226 \pm 0.068$ & $70.244 \pm 0.617$ & $24.109 \pm 0.047$ & $69.265 \pm 0.150$ & $25.798 \pm 0.018$ \\
\hline $78.734 \pm 0.130$ & $23.619 \pm 0.015$ & $79.047 \pm 0.357$ & $23.530 \pm 0.014$ & $78.531 \pm 0.044$ & $25.147 \pm 0.011$ \\
\hline $81.562 \pm 0.090$ & $23.378 \pm 0.012$ & $81.017 \pm 0.042$ & $23.355 \pm 0.013$ & $78.887 \pm 0.036$ & $25.143 \pm 0.014$ \\
\hline \multicolumn{2}{|c|}{$\left[\mathrm{P}_{44414}\right][\mathrm{DBS}]$} & \multicolumn{2}{|c|}{$\left[\mathrm{P}_{4442}\right][\mathrm{DEP}]$} & \multicolumn{2}{|c|}{$\left[\mathrm{P}_{66614}\right][\mathrm{DCA}]$} \\
\hline$T \pm \sigma\left({ }^{\circ} \mathrm{C}\right)$ & $\gamma \pm \sigma\left(\mathrm{mJ} / \mathrm{m}^{2}\right)$ & $T \pm \sigma\left({ }^{\circ} \mathrm{C}\right)$ & $\gamma \pm \sigma\left(\mathrm{mJ} / \mathrm{m}^{2}\right)$ & $T \pm \sigma\left({ }^{\circ} \mathrm{C}\right)$ & $\gamma \pm \sigma\left(\mathrm{mJ} / \mathrm{m}^{2}\right)$ \\
\hline $20.672 \pm 0.152$ & $29.834 \pm 0.015$ & $21.239 \pm 0.069$ & $29.433 \pm 0.006$ & $20.535 \pm 0.195$ & $31.720 \pm 0.019$ \\
\hline $30.726 \pm 0.042$ & $29.274 \pm 0.030$ & $31.082 \pm 0.497$ & $28.471 \pm 0.069$ & $29.939 \pm 0.277$ & $31.074 \pm 0.030$ \\
\hline $40.105 \pm 0.390$ & $28.590 \pm 0.025$ & $39.867 \pm 0.122$ & $27.863 \pm 0.021$ & $39.410 \pm 0.229$ & $30.388 \pm 0.022$ \\
\hline $50.989 \pm 0.775$ & $28.002 \pm 0.045$ & $49.979 \pm 0.133$ & $27.261 \pm 0.026$ & $49.463 \pm 0.153$ & $29.657 \pm 0.013$ \\
\hline $59.531 \pm 0.299$ & $27.498 \pm 0.025$ & $59.729 \pm 0.095$ & $26.712 \pm 0.026$ & $59.067 \pm 0.179$ & $28.950 \pm 0.028$ \\
\hline $69.319 \pm 0.265$ & $26.890 \pm 0.019$ & $69.582 \pm 0.421$ & $26.020 \pm 0.042$ & $69.448 \pm 0.209$ & $28.202 \pm 0.027$ \\
\hline $78.249 \pm 0.256$ & $26.308 \pm 0.035$ & $78.819 \pm 0.404$ & $25.389 \pm 0.024$ & $78.014 \pm 0.569$ & $27.175 \pm 0.053$ \\
\hline $81.693 \pm 0.069$ & $26.091 \pm 0.012$ & $81.711 \pm 0.088$ & $25.171 \pm 0.017$ & $79.099 \pm 0.043$ & $26.938 \pm 0.095$ \\
\hline \multicolumn{6}{|c|}{$\left[\mathrm{P}_{66614}\right][\mathrm{Cl}]$} \\
\hline & $T \pm \sigma\left({ }^{\circ} \mathrm{C}\right)$ & & & $\gamma \pm \sigma\left(\mathrm{mJ} / \mathrm{m}^{2}\right)$ & \\
\hline & $19.941 \pm 0.190$ & & & $30.122 \pm 0.034$ & \\
\hline & $30.750 \pm 0.267$ & & & $29.599 \pm 0.043$ & \\
\hline & $40.443 \pm 0.274$ & & & $28.783 \pm 0.043$ & \\
\hline & $49.355 \pm 0.105$ & & & $28.072 \pm 0.026$ & \\
\hline & $59.625 \pm 0.088$ & & & $27.426 \pm 0.029$ & \\
\hline & $69.388 \pm 0.339$ & & & $26.650 \pm 0.034$ & \\
\hline & $78.150 \pm 0.215$ & & & $25.818 \pm 0.034$ & \\
\hline & $81.296 \pm 0.067$ & & & $25.408 \pm 0.013$ & \\
\hline
\end{tabular}

obtained values were associated with each considered parameter and are reported in Tables 7 and 8.

$$
\sigma_{\mathrm{C}}^{2}(y)=\sum_{i=1}^{N}\left[\frac{\partial f}{\partial x_{i}}\right]^{2} \sigma^{2}\left(x_{i}\right)+2 \sum_{i=1}^{N-1} \sum_{j=i+1}^{N} \frac{\partial f}{\partial x_{i}} \frac{\partial f}{\partial x_{j}} \operatorname{COV}_{x_{i} x_{j}}
$$

\section{RESULTS AND DISCUSSION}

3.1. Surface Tension. Surface tension $(\gamma)$ is a measure of the free energy of a minimum surface area at a boundary layer that separates liquid and vapor phases. Surface tensions of neat phosponium-based ILs are presented in Table 3, adding the standard deviation $(\sigma)$ from at least 10 measurements in each case to the surface tension $(\gamma)$ and temperature $(T)$ average values.

The basic thermodynamic relationship applied to the surface of a homogeneous liquid was analyzed using Gibbs free energy definition, ${ }^{25}$ showing the surface tension linearly decreasing with temperature rise (eq 10).

$$
\gamma=a-b T
$$

The measured surface tensions (Table 4) were fitted to eq 10 where the y-intercept "a" can be read as the surface excess energy $\left(E_{S}\right)$, and the slope "b" can be associated with the surface excess entropy $\left(S_{\mathrm{S}}\right) \cdot{ }^{10}$ In general, the surface tensions of the ILs were much smaller than water and higher than those of most volatile organic solvents. ${ }^{3}$ With regard to the structure-
Table 4. Surface Tension of the Ionic Liquids

\begin{tabular}{ccccc} 
& $E_{\mathrm{S}}(\mathrm{mJ} /$ & $S_{\mathrm{S}}$ & \\
ionic liquids & $\left.\mathrm{m}^{2}\right)$ & $\left(\mathrm{mJ} / \mathrm{m}^{2} \mathrm{~K}\right)$ & eq $(\gamma=a-b T)$ & $R^{2}$ \\
{$\left[\mathrm{P}_{66614}\right]$} & 29.788 & 0.0792 & $29.788-$ & 0.9974 \\
{$\left[(\mathrm{iC} 8)_{2} \mathrm{PO}_{2}\right]$} & & & $0.0792 T$ & \\
{$\left[\mathrm{P}_{66614}\right][\mathrm{BEHP}]$} & 29.126 & 0.0707 & $29.126-$ & 0.9972 \\
& & & $0.0707 T$ & \\
{$\left[\mathrm{P}_{66614}\right]\left[\mathrm{NTf}_{2}\right]$} & 30.846 & 0.0727 & $30.846-$ & 0.9997 \\
& & & $0.0727 T$ & \\
{$\left[\mathrm{P}_{44414}\right][\mathrm{DBS}]$} & 31.108 & 0.0612 & $31.108-$ & 0.9991 \\
& & & $0.0612 T$ & \\
{$\left[\mathrm{P}_{4442}\right][\mathrm{DEP}]$} & 30.681 & 0.0674 & $30.681-$ & 0.9952 \\
& & & $0.0674 T$ & \\
{$\left[\mathrm{P}_{66614}\right][\mathrm{DCA}]$} & 33.452 & 0.0784 & $33.452-$ & 0.9912 \\
& & & $0.0784 T$ & \\
{$\left[\mathrm{P}_{66614}\right][\mathrm{Cl}]$} & 31.805 & 0.0754 & $31.805-$ & 0.9939 \\
& & & $0.0757 T$ & \\
\hline
\end{tabular}

surface tension relationship, variations in surface tension with ion size changes were observed.

A decrease in the size of the anion led to an increase in surface tension, explaining the high values shown by $\left[\mathrm{P}_{66614}\right][\mathrm{DCA}]$ and $\left[\mathrm{P}_{66614}\right][\mathrm{Cl}]$ given the small size of their anion. ${ }^{8}$ Similarly, $\left[\mathrm{P}_{66614}\right]\left[(\mathrm{iC} 8)_{2} \mathrm{PO}_{2}\right]$ and $\left[\mathrm{P}_{66614}\right][\mathrm{BEHP}]$ displayed the lowest values for surface tension according to their high cation and anion alkyl chain length. This fact can be explained by the dispersion of the charge ${ }^{10}$ on a large-sized cation like $\left[\mathrm{P}_{66614}\right]$. In addition, the two ILs with smaller cations $\left(\left[\mathrm{P}_{4442}\right][\mathrm{DEP}]\right.$ and $\left.\left[\mathrm{P}_{44414}\right][\mathrm{DBS}]\right)$ exhibited intermediate values. Figure 3 plots the surface tension values of the 
phosphonium ILs studied versus the temperature, using all data available from the experimental measurements.

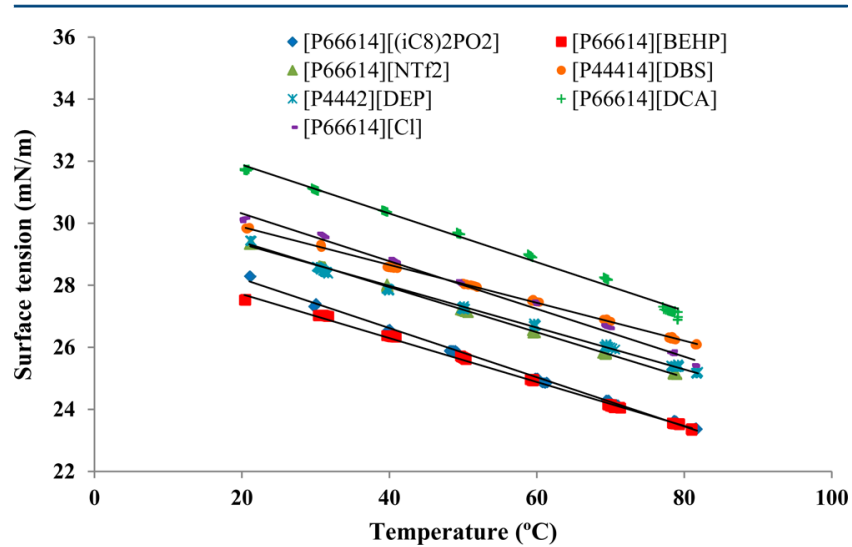

Figure 3. Temperature-dependent surface tensions of phosphoniumbased ionic liquids.

3.2. Contact Angle. Figure 4 shows the evolution of the contact angle during 28 different dynamic sessile drop tests (7 ILs on 4 substrates). In order to measure advancing contact angles, the drop formed was grown for about $180 \mathrm{~s}$ to ensure that the steady state was reached. Analysis of the contact angle evolution of seven ILs on all surfaces studied showed that $\left[\mathrm{P}_{66614}\right]\left[\mathrm{NTf}_{2}\right],\left[\mathrm{P}_{4442}\right][\mathrm{DEP}]$ and $\left[\mathrm{P}_{66614}\right][\mathrm{DCA}]$ reached the steady state sooner than the others.

From a surface point of view (Table 5), high surface energy values are favorable for wetting a surface. Moreover, surfaces become more hydrophilic with increasing polar components, i.e., the contact angle of all ILs on TiN (Figure 4b) is expected to be low due to high total and polar component values, provoking better wetting. ${ }^{23}$ Although similar behavior would be expected for steel (Figure 4a) due to its high polar component, the low value of the total energy negatively affects wettability. In the case of $\mathrm{CrN}$ surface (Figure 4c), higher values of contact angle in comparison with the other substrates were observed for liquids $\left[\mathrm{P}_{66614}\right]\left[(\mathrm{iC} 8)_{2} \mathrm{PO}_{2}\right]$ and $\left[\mathrm{P}_{66614}\right][\mathrm{BEHP}]$. This fact occurs because both low values of polar and total components adversely affect wettability. Finally, it is possible to explain the similar trend of contact angle behavior on $\mathrm{ZrN}$ and steel surfaces (Figure $4 \mathrm{~d}, \mathrm{a}$, respectively) because of their surface energy intermediate behavior.

With the aim of complementing the results shown in Figure 4 , Table 6 shows the average steady state contact angle and the standard deviations for the ILs studied on the four surfaces (AISI 52100 steel, TiN, CrN, and ZrN).

Analyzing the obtained results for the most hydrophobic surface used in this work $(\mathrm{ZrN}),\left[\mathrm{P}_{66614}\right]\left[(\mathrm{iC} 8)_{2} \mathrm{PO}_{2}\right]$ and $\left[\mathrm{P}_{66614}\right][\mathrm{BEHP}]$ showed the lowest contact angle values whereas $\left[\mathrm{P}_{4442}\right][\mathrm{DEP}]$ and $\left[\mathrm{P}_{66614}\right][\mathrm{DCA}]$ had the highest ones. In addition, $\left[\mathrm{P}_{66614}\right]\left[\mathrm{NTf}_{2}\right], \quad\left[\mathrm{P}_{44414}\right][\mathrm{DBS}]$ and $\left[\mathrm{P}_{66614}\right][\mathrm{Cl}]$ had intermediate contact angles. However, comparing these values with those reported in the literature is not possible due to the absence of data on the same surfaces. Changes in drop volume, type of needle, measuring software, analysis lab, etc., can affect the results obtained. ${ }^{59}$ Since all surfaces are characterized by time-dependent contact angles, this property does not contain enough information about the solid-liquid interaction resulting in the inability to define the wetting properties. ${ }^{12}$ Therefore, additional parameters are
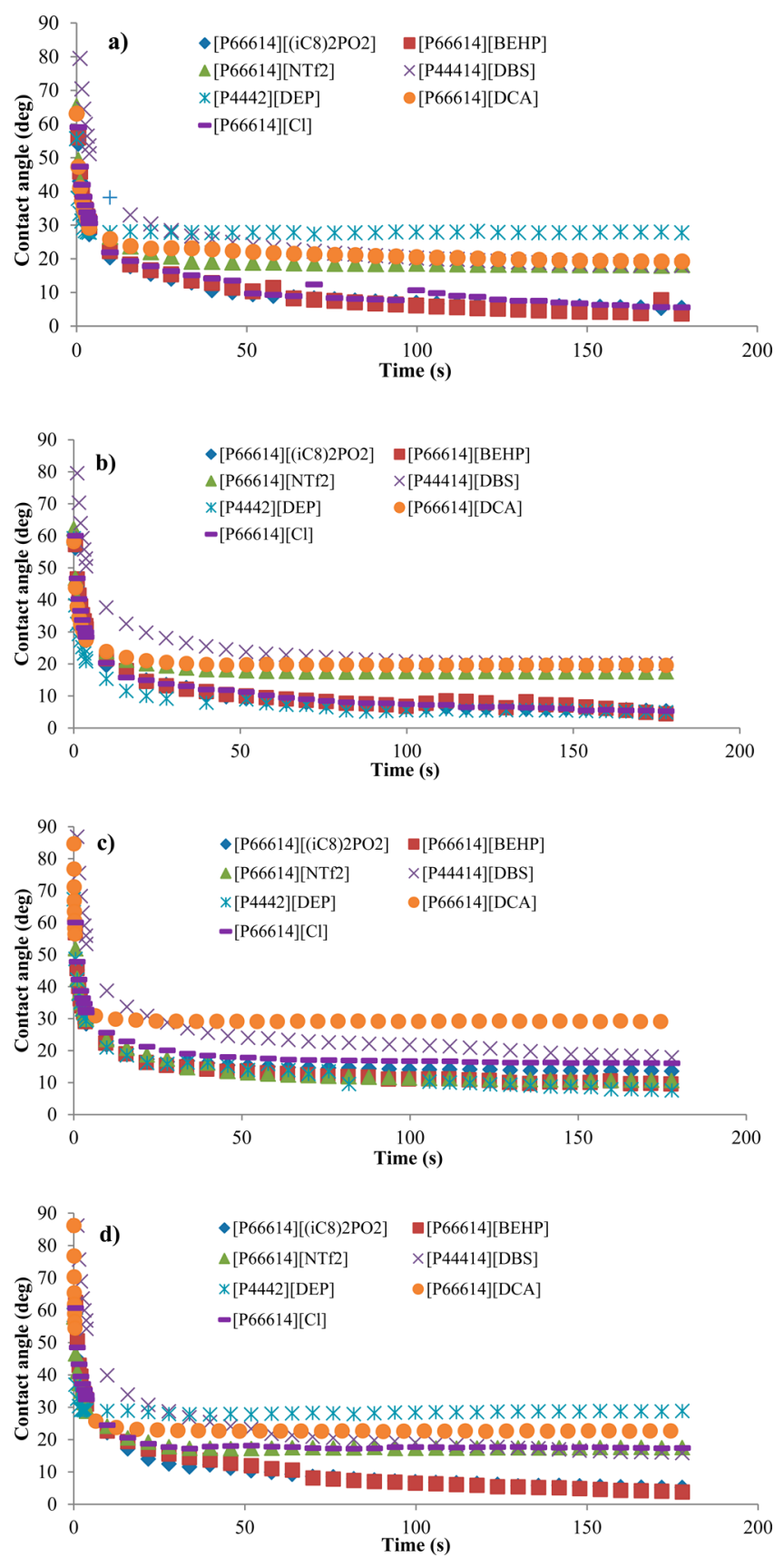

Figure 4. Evolution of the advancing contact angle of the ionic liquids on four different surfaces: (a) Steel, (b) TiN, (c) CrN, and (d) ZrN.

Table 5. Surface Energy Found in the Literature ${ }^{20,58}$ for All Substrates Used at $293 \mathrm{~K}$

\begin{tabular}{lccc}
\multicolumn{1}{c}{ Surfaces } & $\gamma_{\mathrm{S}}\left(\mathrm{mJ} / \mathrm{m}^{2}\right)$ & $\gamma_{\mathrm{S}}^{\mathrm{d}}\left(\mathrm{mJ} / \mathrm{m}^{2}\right)$ & $\gamma_{\mathrm{S}}^{\text {nd }}\left(\mathrm{mJ} / \mathrm{m}^{2}\right)$ \\
AISI 52100 steel & 43.4 & 31.2 & 12.2 \\
ZrN & 52.2 & 48.1 & 4.1 \\
$\mathrm{CrN}$ & 44.5 & 39.1 & 5.4 \\
$\mathrm{TiN}$ & 63.2 & 50.2 & 13 \\
\hline
\end{tabular}

recommended in order to improve the understanding and explanation of wettability.

3.3. Polarity Fraction and SP. From a lubrication point of view, the use of ILs as an additive to base oils is limited by their solubility. Therefore, the estimation of polarity related parameters of the ILs, like polarity fraction, can be useful in 
Table 6. Steady State Values of Contact Angles for the Ionic Liquids

\begin{tabular}{|c|c|c|c|c|}
\hline & steel & TiN & $\mathrm{CrN}$ & $\mathrm{ZrN}$ \\
\hline short name & $\theta \pm \sigma(\operatorname{deg})$ & $\theta \pm \sigma(\operatorname{deg})$ & $\theta \pm \sigma(\operatorname{deg})$ & $\theta \pm \sigma(\operatorname{deg})$ \\
\hline$\left[\mathrm{P}_{66614}\right]\left[(\mathrm{iC} 8)_{2} \mathrm{PO}_{2}\right]$ & $5.177 \pm 0.219$ & $5.787 \pm 0.237$ & $13.946 \pm 0.076$ & $5.536 \pm 0.256$ \\
\hline$\left[\mathrm{P}_{66614}\right][\mathrm{BEHP}]$ & $4.113 \pm 0.243$ & $6.701 \pm 0.626$ & $9.982 \pm 0.307$ & $4.362 \pm 0.286$ \\
\hline$\left[\mathrm{P}_{66614}\right]\left[\mathrm{NTf}_{2}\right]$ & $18.158 \pm 0.121$ & $12.957 \pm 0.224$ & $17.417 \pm 0.064$ & $17.460 \pm 0.089$ \\
\hline$\left[\mathrm{P}_{44414}\right][\mathrm{DBS}]$ & $18.345 \pm 0.223$ & $20.350 \pm 0.134$ & $19.409 \pm 0.399$ & $17.742 \pm 0.129$ \\
\hline$\left[\mathrm{P}_{4442}\right][\mathrm{DEP}]$ & $27.850 \pm 0.124$ & $5.328 \pm 0.220$ & $8.314 \pm 0.376$ & $28.740 \pm 0.060$ \\
\hline$\left[\mathrm{P}_{66614}\right][\mathrm{DCA}]$ & $19.390 \pm 0.120$ & $19.589 \pm 0.027$ & $29.096 \pm 0.249$ & $22.689 \pm 0.061$ \\
\hline$\left[\mathrm{P}_{66614}\right][\mathrm{Cl}]$ & $5.299 \pm 0.276$ & $5.848 \pm 0.357$ & $16.182 \pm 0.107$ & $17.510 \pm 0.170$ \\
\hline
\end{tabular}

Table 7. Polarity of the Ionic Liquids at $293 \mathrm{~K}$

\begin{tabular}{|c|c|c|c|c|}
\hline \multirow[b]{2}{*}{ ionic liquids } & \multicolumn{4}{|c|}{$\mathrm{ZrN}$} \\
\hline & $\gamma_{\mathrm{L}} \pm \sigma\left(\mathrm{mJ} / \mathrm{m}^{2}\right)$ & $\gamma_{\mathrm{L}}^{\mathrm{d}} \pm \sigma_{\mathrm{C}}\left(\mathrm{mJ} / \mathrm{m}^{2}\right)$ & $\gamma_{\mathrm{L}}^{\mathrm{nd}} \pm \sigma_{\mathrm{C}}\left(\mathrm{mJ} / \mathrm{m}^{2}\right)$ & $\mathrm{PF} \pm \sigma_{\mathrm{C}}$ \\
\hline$\left[\mathrm{P}_{66614}\right]\left[(\mathrm{iC} 8)_{2} \mathrm{PO}_{2}\right]$ & $28.289 \pm 0.006$ & $16.560 \pm 0.410$ & $11.729 \pm 0.410$ & $0.415 \pm 0.014$ \\
\hline$\left[\mathrm{P}_{66614}\right][\mathrm{BEHP}]$ & $27.525 \pm 0.007$ & $15.705 \pm 0.342$ & $11.820 \pm 0.342$ & $0.429 \pm 0.012$ \\
\hline$\left[\mathrm{P}_{66614}\right]\left[\mathrm{NTf}_{2}\right]$ & $29.327 \pm 0.009$ & $17.067 \pm 0.467$ & $12.260 \pm 0.467$ & $0.418 \pm 0.016$ \\
\hline$\left[\mathrm{P}_{44414}\right][\mathrm{DBS}]$ & $29.834 \pm 0.015$ & $17.635 \pm 0.710$ & $12.199 \pm 0.710$ & $0.409 \pm 0.024$ \\
\hline$\left[\mathrm{P}_{4442}\right][\mathrm{DEP}]$ & $29.433 \pm 0.006$ & $15.860 \pm 0.488$ & $13.573 \pm 0.488$ & $0.461 \pm 0.017$ \\
\hline$\left[\mathrm{P}_{66614}\right][\mathrm{DCA}]$ & $31.720 \pm 0.019$ & $19.331 \pm 0.474$ & $12.389 \pm 0.474$ & $0.391 \pm 0.015$ \\
\hline$\left[\mathrm{P}_{66614}\right][\mathrm{Cl}]$ & $30.122 \pm 0.034$ & $18.000 \pm 0.943$ & $12.122 \pm 0.943$ & $0.402 \pm 0.031$ \\
\hline
\end{tabular}

Table 8. Spreading Parameter Uncertainty

\begin{tabular}{|c|c|c|c|c|}
\hline & $\mathrm{ZrN}$ & $\mathrm{CrN}$ & steel & TiN \\
\hline ionic liquids & $\mathrm{SP} \pm \sigma_{\mathrm{C}}$ & $\mathrm{SP} \pm \sigma_{\mathrm{C}}$ & $\mathrm{SP} \pm \sigma_{\mathrm{C}}$ & $\mathrm{SP} \pm \sigma_{\mathrm{C}}$ \\
\hline$\left[\mathrm{P}_{66614}\right]\left[(\mathrm{iC} 8)_{2} \mathrm{PO}_{2}\right]$ & $13.737 \pm 0.740$ & $10.231 \pm 0.689$ & $12.807 \pm 0.701$ & $25.783 \pm 0.834$ \\
\hline$\left[\mathrm{P}_{66614}\right][\mathrm{BEHP}]$ & $13.843 \pm 0.632$ & $10.490 \pm 0.588$ & $13.239 \pm 0.595$ & $25.899 \pm 0.709$ \\
\hline$\left[\mathrm{P}_{66614}\right]\left[\mathrm{NTf}_{2}\right]$ & $12.829 \pm 0.829$ & $9.284 \pm 0.771$ & $11.957 \pm 0.784$ & $25.136 \pm 0.934$ \\
\hline$\left[\mathrm{P}_{44414}\right][\mathrm{DBS}]$ & $12.725 \pm 1.244$ & $9.082 \pm 1.159$ & $11.644 \pm 1.182$ & $25.025 \pm 1.405$ \\
\hline$\left[\mathrm{P}_{4442}\right][\mathrm{DEP}]$ & $11.294 \pm 0.891$ & $8.061 \pm 0.825$ & $11.360 \pm 0.826$ & $24.134 \pm 0.990$ \\
\hline$\left[\mathrm{P}_{66614}\right][\mathrm{DCA}]$ & $11.800 \pm 0.796$ & $7.903 \pm 0.744$ & $10.265 \pm 0.765$ & $24.244 \pm 0.905$ \\
\hline$\left[\mathrm{P}_{66614}\right][\mathrm{Cl}]$ & $12.704 \pm 1.638$ & $8.995 \pm 1.528$ & $11.474 \pm 1.563$ & $24.982 \pm 1.855$ \\
\hline
\end{tabular}

order to predict the solubility of ILs in base oils. In order to obtain this parameter, both components of the surface tension (polar and dispersive) were calculated. The dispersive component of the surface tension $\left(\gamma_{\mathrm{L}}^{\mathrm{d}}\right)$ was obtained from data of the seven ILs measured on the $\mathrm{ZrN}$ surface (Table 5). The negligible polar $\left(\gamma_{S}^{\text {nd }}\right)$ component of the surface energy allows for using eq 5 or OWRK $^{60}$ (Owens-Wendt-RabelKaelble) method. The polar or nondispersive component of surface tension was determined using the Fowkes ${ }^{22}$ method (eq $1)$. The polarity fraction (PF) is defined as the ratio between the nondispersive or polar component $\left(\gamma_{L}^{\text {nd }}\right)$ and the total surface tension $\left(\gamma_{\mathrm{L}}\right)$. Table 7 summarizes the results obtained applying eq 1 and eq 5 for the ILs used in this study, while using eq 9 to obtain the combined uncertainty associated with each one of these calculated parameters.

As expected, ILs with large cation and anion alkyl chains $\left(\left[\mathrm{P}_{66614}\right]\left[(\mathrm{iC} 8)_{2} \mathrm{PO}_{2}\right]\right.$ and $\left.\left[\mathrm{P}_{66614}\right][\mathrm{BEHP}]\right)$ had the lowest nondispersive component for surface tension. In addition, the polarity fraction seemed to be more affected by the cation type according to the highest value obtained for $\left[\mathrm{P}_{4442}\right][\mathrm{DEP}]$, whereas the others containing similar cations showed closer PF values. This trend may be associated with the length of both cation and anion alkyl chains, which is inversely proportional to the nondispersive (polar) component of surface tension.

These results explain the behavior of $\left[\mathrm{P}_{66614}\right]\left[\mathrm{NTf}_{2}\right]$, $\left[\mathrm{P}_{4442}\right][\mathrm{DEP}]$ and $\left[\mathrm{P}_{66614}\right][\mathrm{DCA}]$ seen in Figure 4 . These three ILs reached the steady state earlier than the other lubricants due to the higher obtained polar components for surface tension $\left(\gamma_{\mathrm{L}}^{\text {nd }}\right)$. Although the polarity fractions were between 0.39 and 0.46, when compared with values for traditional polar liquids like water (0.70) and glycerol (0.47), the ILs used in this work can be considered as moderately polar. ${ }^{10}$ Due to the similarity in the polarity fraction values, no conclusions can be made about the solubility of these ILs in base oils.

The nature of spreading is manifested in two completely opposite behaviors: spreading-wetting (time dependent contact angle and positive SP) or adhesion-wetting (constant contact angle, negative SP, no cases in this study). A negative value for the SP means that cohesion work between molecules within the ILs is greater than on the solid-liquid interface. ${ }^{12,13,20}$ Therefore, lower values of SP indicate that a liquid will spread less easily over the surface. However, it is true that a timedependent contact angle has a positive SP, which occurred in all 28 IL-substrate combinations studied in this work (Table 8 and Figure 5), making the TiN surface much better than the others from a wetting point of view.

Analyzing the results obtained, it is possible to discern a trend for all surfaces studied: $\left[\mathrm{P}_{66614}\right]\left[(\mathrm{iC} 8)_{2} \mathrm{PO}_{2}\right]$ and $\left[\mathrm{P}_{66614}\right][\mathrm{BEHP}]$ had the highest values, thus having the best wettability on hydrophobic surfaces. Furthermore, the differences between ILs were more noticeable in the most hydrophobic surfaces ( $\mathrm{CrN}$ and $\mathrm{ZrN}$ ), thus making a comparison more difficult for the less hydrophobic one 


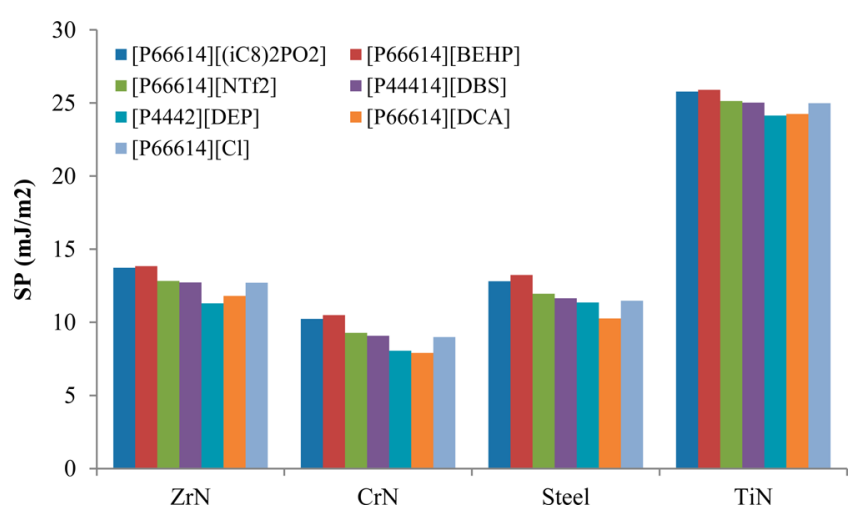

Figure 5. Spreading parameter of the ionic liquids.

(TiN) because the values were very close and the error was in the same magnitude order as the differences between SP values.

The wetting parameters studied above are very important whenever a solid-liquid interface is present, which usually occurs in different applications. ${ }^{12,20}$ Although this scenario is not usually encountered in tribology, the study of wetting could be useful in order to properly design tribological contacts. ${ }^{13}$ The tribological behavior of the same phosphonium-based ILs has been tested in a previous work. ${ }^{5}\left[\mathrm{P}_{4442}\right][\mathrm{DEP}]$ presented the worst wetting properties on the steel surface (contact angle around $28^{\circ}, E_{\mathrm{S}}=31.11 \mathrm{~mJ} / \mathrm{m}^{2}, \mathrm{SP}=11.4$ and 0.46 of polarity fraction), but the reactivity of the phosphate anion provided better friction reduction for this IL $(\mathrm{CoF}=0.06)$ in comparison with the other four ILs $(\mathrm{CoF}>0.07)$. Despite the fact that no critical relationship between wetting behavior and tribological performance with these specific ILs was found after making the comparison, wettability is desired $(\mathrm{SP}>0)$ in order to achieve proper lubrication.

\section{CONCLUSIONS}

From the study of the wetting properties of seven phosphonium-based ILs- $\left[\mathrm{P}_{66614}\right]\left[(\mathrm{iC} 8)_{2} \mathrm{PO}_{2}\right],\left[\mathrm{P}_{66614}\right]$ $[\mathrm{BEHP}],\left[\mathrm{P}_{66614}\right]\left[\mathrm{NTf}_{2}\right], \quad\left[\mathrm{P}_{44414}\right][\mathrm{DBS}], \quad\left[\mathrm{P}_{4442}\right][\mathrm{DEP}]$, $\left[\mathrm{P}_{66614}\right][\mathrm{DCA}]$ and $\left[\mathrm{P}_{66614}\right][\mathrm{Cl}]$ - on four different surfaces (AISI 52100 steel and three PVD coatings $\mathrm{CrN}$, TiN, and $\mathrm{ZrN}$ ) some conclusions can be drawn:

(1) $\left[\mathrm{P}_{66614}\right][\mathrm{DCA}],\left[\mathrm{P}_{44414}\right][\mathrm{DBS}]$, and $\left[\mathrm{P}_{66614}\right][\mathrm{Cl}]$ showed higher surface tension values while $\left[\mathrm{P}_{66614}\right]\left[(\mathrm{iC} 8)_{2} \mathrm{PO}_{2}\right]$ and $\left[\mathrm{P}_{66614}\right][\mathrm{BEHP}]$ exhibited lower ones. The difference between the lowest and the highest values was about $13 \%$. Increasing alkyl chain length and anion size causes a dispersion of the charge and the surface tension values should decrease.

(2) Steel and ZrN surfaces exhibited the expected trend on hydrophobic surfaces: ILs with the lowest surface tensions led to the lowest contact angles. In addition, a drop of contact angle values around $85 \%$ between $\left[\mathrm{P}_{4442}\right][\mathrm{DEP}]$ and $\left[\mathrm{P}_{66614}\right][\mathrm{BEHP}]$ was achieved on the two surfaces mentioned above.

(3) PF behavior of all ILs studied were in a $15 \%$ narrow range $(0.39-0.46)$ between $\left[\mathrm{P}_{66614}\right][\mathrm{DCA}]$ and $\left[\mathrm{P}_{4442}\right][\mathrm{DEP}]$. Although these values were much lower than the value for water $(0.7)$, these phosphonium-based ILs can be considered as moderately polar.

(4) The SP values of all ILs on TiN surface were two times higher than the values obtained for steel and $\mathrm{ZrN}$ ones, and 2.5 times higher than $\mathrm{CrN}$ surface. These results showed that TiN coating displays the best wettability with these ILs. In addition, the SP results were in agreement with the ones obtained for contact angle and surface tension. Therefore, $\left[\mathrm{P}_{66614}\right]\left[(\mathrm{iC} 8)_{2} \mathrm{PO}_{2}\right]$ and $\left[\mathrm{P}_{66614}\right][\mathrm{BEHP}]$ showed the highest $\mathrm{SP}$ values besides the lowest contact angle and surface tension data. All ILs "wet" the surfaces $(\mathrm{SP}>0)$ and differences between the highest and lowest values of this parameter for each surface ranged from about $7 \%$ for $\mathrm{TiN}$ to almost $25 \%$ for CrN. Finally, this parameter could be helpful for understanding the wetting behavior of ILs on these surfaces, especially due to the spreading-wetting behavior found in this research.

\section{ASSOCIATED CONTENT}

\section{S Supporting Information}

The Supporting Information is available free of charge on the ACS Publications website at DOI: 10.1021/acs.iecr.6b00821.

Previous works on wettability of ionic liquids (Table S1); images during the advancement of sessile drop on the steel and coated surfaces (Table S2). (PDF)

\section{AUTHOR INFORMATION}

\section{Corresponding Author}

*E-mail: aehernandez@uniovi.es.

\section{Notes}

The authors declare no competing financial interest.

\section{ACKNOWLEDGMENTS}

The authors would like to thank the Ministry of Economy and Competitiveness (Spain) and FICYT (Foundation for the Promotion in Asturias of the Applied Scientific Research and Technology) for supporting the research projects STARLUBE (DPI2013-48348-C2-1-R) and GRUPIN14-023, respectively, under which this research was developed. The Emulsions and Interfacial Phenomena research group from University of Oviedo as well as Professors Celestino Ordóñez Galán and Manuel Montenegro Hermida are also acknowledged.

\section{NOMENCLATURE}

\begin{tabular}{|c|c|}
\hline$\theta$ & contact angle, deg \\
\hline$\sigma$ & standard deviation, deg or $\mathrm{mJ} / \mathrm{m}^{2}$ \\
\hline $\begin{array}{l}\sigma_{\mathrm{c}} \\
\mathrm{COV}\end{array}$ & $\begin{array}{l}\text { combined uncertainty, } \mathrm{mJ} / \mathrm{m}^{2} \text { or - } \\
\text { covariance, - }\end{array}$ \\
\hline & surface tension, $\mathrm{mJ} / \mathrm{m}^{2}$ \\
\hline$=\gamma_{\mathrm{LV}}^{\mathrm{d}}$ & $\begin{array}{l}\text { dispersive component of surface tension, } \mathrm{mJ} / \\
\mathrm{m}^{2}\end{array}$ \\
\hline$\gamma^{\text {nd }}=\gamma_{\mathrm{L}}^{\mathrm{nd}}=\gamma_{\mathrm{LV}}^{\mathrm{nd}}$ & polar component of surface tension, $\mathrm{mJ} / \mathrm{m}^{2}$ \\
\hline$W_{\mathrm{SL}}$ & $\begin{array}{l}\text { work of adhesion (solid-liquid interface), } \mathrm{mJ} / \\
\mathrm{m}^{2}\end{array}$ \\
\hline$W_{\mathrm{C}}$ & work of cohesion (liquid), $\mathrm{mJ} / \mathrm{m}^{2}$ \\
\hline$\gamma_{S}=$ & total surface energy, $\mathrm{mJ} / \mathrm{m}^{2}$ \\
\hline & $\begin{array}{l}\text { dispersive component of surface energy, } \mathrm{mJ} / \\
\mathrm{m}^{2}\end{array}$ \\
\hline$\gamma_{S}^{\text {nd }}$ & polar component of surface energy, $\mathrm{mJ} / \mathrm{m}^{2}$ \\
\hline$\gamma_{\mathrm{SL}}$ & solid-liquid interfacial tension, $\mathrm{mJ} / \mathrm{m}^{2}$ \\
\hline $\begin{array}{l}\gamma_{L}=\gamma_{L V} \\
E_{S}\end{array}$ & $\begin{array}{l}\text { vapor-liquid interfacial tension, } \mathrm{mJ} / \mathrm{m}^{2} \\
\text { surface excess energy, } \mathrm{mJ} / \mathrm{m}^{2}\end{array}$ \\
\hline$S_{\mathrm{S}}$ & surface excess entropy, $\mathrm{mJ} / \mathrm{m}^{2} \cdot \mathrm{K}$ \\
\hline$S_{\mathrm{P}}$ & spreading parameter, $\mathrm{mJ} / \mathrm{m}^{2}$ \\
\hline & polarity fraction, - \\
\hline
\end{tabular}


CoF friction coefficient, -

\section{REFERENCES}

(1) Castejón, H. J.; Wynn, T. J.; Marcin, Z. M. Wetting and Tribological Properties of Ionic Liquids. J. Phys. Chem. B 2014, 118, 3661.

(2) Delcheva, I.; Ralston, J.; Beattie, D. A.; Krasowska, M. Static and Dynamic Wetting Behaviour of Ionic Liquids. Adv. Colloid Interface Sci. 2015, 222, 162.

(3) Zhang, X.; Huo, F.; Liu, X.; Dong, K.; He, H.; Yao, X.; Zhang, S. Influence of Microstructure and Interaction on Viscosity of Ionic Liquids. Ind. Eng. Chem. Res. 2015, 54 (13), 3505.

(4) Carrera, G. V. S. M.; Afonso, C. a M.; Branco, L. C. Interfacial Properties, Densities, and Contact Angles of Task Specific Ionic Liquids. J. Chem. Eng. Data 2010, 55 (2), 609.

(5) Hernández Battez, A.; Bartolomé, M.; Blanco, D.; Viesca, J. L.; Fernández-González, A.; González, R. Phosphonium Cation-Based Ionic Liquids as Neat Lubricants: Physicochemical and Tribological Performance. Tribol. Int. 2016, 95, 118.

(6) Alcalde, R.; García, G.; Atilhan, M.; Aparicio, S. Systematic Study on the Viscosity of Ionic Liquids: Measurement and Prediction. Ind. Eng. Chem. Res. 2015, 54, 10918.

(7) Shirota, H.; Mandai, T.; Fukazawa, H.; Kato, T. Comparison between Dicationic and Monocationic Ionic Liquids: Liquid Density, Thermal Properties, Surface Tension, and Shear Viscosity. J. Chem. Eng. Data 2011, 56 (5), 2453.

(8) Freire, M. G.; Carvalho, P. J.; Fernandes, A. M.; Marrucho, I. M.; Queimada, A. J.; Coutinho, J. A. P. Surface Tensions of Imidazolium Based Ionic Liquids: Anion, Cation, Temperature and Water Effect. J. Colloid Interface Sci. 2007, 314 (2), 621.

(9) Poleski, M.; Luczak, J.; Aranowski, R.; Jungnickel, C. Wetting of Surfaces with Ionic Liquids. Physicochem. Probl. Miner. Process. 2013, 49 (1), 277.

(10) Restolho, J.; Mata, J. L.; Saramago, B. On the Interfacial Behavior of Ionic Liquids: Surface Tensions and Contact Angles. J. Colloid Interface Sci. 2009, 340 (1), 82.

(11) Matos, M.; Lobo, A.; Benito, J. M.; Coca, J.; Pazos, C. Extending the Useful Life of Metalworking Fluids in a Copper Wire Drawing Industry by Monitoring Their Functional Properties. Tribol. Trans. 2012, 55 (5), 685.

(12) Kalin, M.; Polajnar, M. The Correlation between the Surface Energy, the Contact Angle and the Spreading Parameter, and Their Relevance for the Wetting Behaviour of DLC with Lubricating Oils. Tribol. Int. 2013, 66, 225.

(13) Kalin, M.; Polajnar, M. The Effect of Wetting and Surface Energy on the Friction and Slip in Oil-Lubricated Contacts. Tribol. Lett. 2013, 52 (2), 185.

(14) Hernández Battez, A.; González, R.; Viesca, J. L.; FernándezGonzález, A.; Hadfield, M. Lubrication of PVD Coatings with EthylDimethyl-2-Methoxyethylammonium Tris(pentafluoroethyl)trifluorophosphate. Tribol. Int. 2013, 58, 71.

(15) González, R.; Hernández Battez, A.; Blanco, D.; Viesca, J. L.; Fernández-González, A. Lubrication of TiN, CrN and DLC PVD Coatings with 1-Butyl-1- Methylpyrrolidinium Tris(pentafluoroethyl)trifluorophosphate. Tribol. Lett. 2010, 40 (2), 269.

(16) Blanco, D.; Battez, A. H.; Viesca, J. L.; González, R.; FernándezGonzález, A. Lubrication of CrN Coating with Ethyl-Dimethyl-2Methoxyethylammonium Tris(pentafluoroethyl)trifluorophosphate Ionic Liquid as Additive to PAO 6. Tribol. Lett. 2011, 41 (1), 295.

(17) Blanco, D.; González, R; Hernández Battez, A.; Viesca, J. L.; Fernández-Gonzlez, A. Use of Ethyl-Dimethyl-2-Methoxyethylammonium Tris(pentafluoroethyl) Trifluorophosphate as Base Oil Additive in the Lubrication of TiN PVD Coating. Tribol. Int. 2011, 44 (5), 645.

(18) González, R; Battez, A. H.; Viesca, J. L.; Higuera-Garrido, A.; Fernández-González, A. Lubrication of DLC Coatings with Two Tris(pentafluoroethyl)trifluorophosphate Anion-Based Ionic Liquids. Tribol. Trans. 2013, 56 (5), 887.
(19) Carlsson, P.; Olsson, M. PVD Coatings for Sheet Metal Forming Processes-a Tribological Evaluation. Surf. Coat. Technol. 2006, 200 (14-15), 4654.

(20) Kalin, M.; Polajnar, M. The Wetting of Steel, DLC Coatings, Ceramics and Polymers with Oils and Water: The Importance and Correlations of Surface Energy, Surface Tension, Contact Angle and Spreading. Appl. Surf. Sci. 2014, 293, 97.

(21) Batchelor, T.; Cunder, J.; Fadeev, A. Y. Wetting Study of Imidazolium Ionic Liquids. J. Colloid Interface Sci. 2009, 330 (2), 415.

(22) Fowkes, F. M. Attractive Forces at Interfaces. Ind. Eng. Chem. 1964, 56 (12), 40.

(23) Lugscheider, E.; Bobzin, K. The Influence on Surface Free Energy of PVD-Coatings. Surf. Coat. Technol. 2001, 142-144, 755.

(24) Sedev, R. Surface Tension, Interfacial Tension and Contact Angles of Ionic Liquids. Curr. Opin. Colloid Interface Sci. 2011, 16 (4), 310.

(25) Kilaru, P.; Baker, G. A.; Scovazzo, P. Density and Surface Tension Measurements of Imidazolium-, Quaternary Phosphonium-, and Ammonium-Based Room-Temperature Ionic Liquids: Data and Correlations. J. Chem. Eng. Data 2007, 52 (6), 2306.

(26) Tiago, G.; Restolho, J.; Forte, A.; Colaço, R.; Branco, L. C.; Saramago, B. Novel Ionic Liquids for Interfacial and Tribological Applications. Colloids Surf., A 2015, 472, 1.

(27) Restolho, J.; Mata, J. L.; Saramago, B. Choline Based Ionic Liquids: Interfacial Properties of RTILs with Strong Hydrogen Bonding. Fluid Phase Equilib. 2012, 322-323, 142.

(28) Espinosa, T.; Sanes, J.; Jiménez, A. E.; Bermúdez, M. D. Surface Interactions, Corrosion Processes and Lubricating Performance of Protic and Aprotic Ionic Liquids with OFHC Copper. Appl. Surf. Sci. 2013, 273, 578

(29) Tariq, M.; Freire, M. G.; Saramago, B.; Coutinho, J. A. P.; Lopes, J. N. C.; Rebelo, L. P. N. Surface Tension of Ionic Liquids and Ionic Liquid Solutions. Chem. Soc. Rev. 2012, 41 (2), 829.

(30) Almeida, H. F. D.; Carvalho, P. J.; Kurnia, K. A.; Lopes-da-Silva, J. A.; Coutinho, J. A. P.; Freire, M. G. Surface Tensions of Ionic Liquids: Non-Regular Trend along the Number of Cyano Groups. Fluid Phase Equilib. 2016, 409, 458.

(31) Pereira, M. M.; Kurnia, K. A.; Sousa, F. L.; Silva, N. J. O.; Lopesda-Silva, J. A.; Coutinho, J. A. P.; Freire, M. G. Contact Angles and Wettability of Ionic Liquids on Polar and Non-Polar Surfaces. Phys. Chem. Chem. Phys. 2015, 17 (47), 31653.

(32) Koller, T. M.; Rausch, M. H.; Pohako-esko, K.; Wasserscheid, P.; Fro, A. P. Surface Tension of Tricyanomethanide- and Tetracyanoborate-Based Imidazolium Ionic Liquids by Using the Pendant Drop Method. J. Chem. Eng. Data 2015, 60 (9), 2665-2673.

(33) Bhattacharjee, A.; Lopes-da-Silva, J. A.; Freire, M. G.; Coutinho, J. A. P.; Carvalho, P. J. Thermophysical Properties of PhosphoniumBased Ionic Liquids. Fluid Phase Equilib. 2015, 400, 103.

(34) Shah, S. N.; Lethesh, K. C.; Mutalib, M. I. A.; Pilus, R. B. M. Evaluation of Thermophysical Properties of Imidazolium-Based Phenolate Ionic Liquids. Ind. Eng. Chem. Res. 2015, 54 (14), 3697.

(35) Bhattacharjee, A.; Luis, A.; Santos, J. H.; Lopes-da-Silva, J. A.; Freire, M. G.; Carvalho, P. J.; Coutinho, J. A. P. Thermophysical Properties of Sulfonium- and Ammonium-Based Ionic Liquids. Fluid Phase Equilib. 2014, 381, 36.

(36) Bhattacharjee, A.; Carvalho, P. J.; Coutinho, J. A. P. The Effect of the Cation Aromaticity upon the Thermophysical Properties of Piperidinium- and Pyridinium-Based Ionic Liquids. Fluid Phase Equilib. 2014, 375, 80.

(37) Almeida, H. F. D.; Freire, M. G.; Fernandes, A. M.; Lopes-daSilva, J. A. J. A.; Morgado, P.; Shimizu, K.; Filipe, E. J. M.; Canongia Lopes, J. N.; Santos, L. M. N. B. F.; Coutinho, J. A. P. Cation Alkyl Side Chain Length and Symmetry Effects on the Surface Tension of Ionic Liquids. Langmuir 2014, 30 (22), 6408.

(38) Ghatee, M. H.; Bahrami, M.; Khanjari, N. Measurement and Study of Density, Surface Tension, and Viscosity of Quaternary Ammonium-Based Ionic Liquids ([N222(n)]Tf2N. J. Chem. Thermodyn. 2013, 65, 42. 
(39) Bittner, B.; Wrobel, R. J.; Milchert, E. Physical Properties of Pyridinium Ionic Liquids. J. Chem. Thermodyn. 2012, 55, 159.

(40) Almeida, H. F. D.; Passos, H.; Lopes-Da-Silva, J. A.; Fernandes, A. M.; Freire, M. G.; Coutinho, J. A. P. Thermophysical Properties of Five Acetate-Based Ionic Liquids. J. Chem. Eng. Data 2012, 57 (11), 3005.

(41) Capelo, S. B.; Méndez-Morales, T.; Carrete, J.; López Lago, E.; Vila, J.; Cabeza, O.; Rodríguez, J. R.; Turmine, M.; Varela, L. M. Effect of Temperature and Cationic Chain Length on the Physical Properties of Ammonium Nitrate-Based Protic Ionic Liquids. J. Phys. Chem. B 2012, 116 (36), 11302.

(42) Xu, A.; Wang, J.; Zhang, Y.; Chen, Q. Effect of Alkyl Chain Length in Anions on Thermodynamic and Surface Properties of 1Butyl-3-Methylimidazolium Carboxylate Ionic Liquids. Ind. Eng. Chem. Res. 2012, 51 (8), 3458.

(43) Almeida, H. F. D.; Lopes-Da-Silva, J. A.; Freire, M. G.; Coutinho, J. A. P. Surface Tension and Refractive Index of Pure and Water-Saturated Tetradecyltrihexylphosphonium-Based Ionic Liquids. J. Chem. Thermodyn. 2013, 57, 372.

(44) Neves, C. M. S. S.; Carvalho, P. J.; Freire, M. G.; Coutinho, J. A. P. Thermophysical Properties of Pure and Water-Saturated Tetradecyltrihexylphosphonium-Based Ionic Liquids. J. Chem. Thermodyn. 2011, 43 (6), 948.

(45) Tong, J.; Yang, H. X.; Liu, R. J.; Li, C.; Xia, L. X.; Yang, J. Z. Determination of the Enthalpy of Vaporization and Prediction of Surface Tension for Ionic Liquid 1-Alkyl-3-methylimidazolium Propionate $[\mathrm{Cnmim}][$ Pro $](\mathrm{n}=4,5,6)$. J. Phys. Chem. B 2014, 118, 12972-78.

(46) Fang, D. W.; Yan, Q.; Li, D.; Xia, L. X.; Zang, S. L. Estimation of physicochemical properties of 1-alkyl-3-methylimidazolium glutamate. J. Chem. Thermodyn. 2014, 79, 12-18.

(47) Somers, A. E.; Khemchandani, B.; Howlett, P. C.; Sun, J.; Macfarlane, D. R.; Forsyth, M. Ionic Liquids as Antiwear Additives in Base Oils: Influence of Structure on Miscibility and Antiwear Performance for Steel on Aluminum. ACS Appl. Mater. Interfaces 2013, 5 (22), 11544.

(48) Qu, J.; Bansal, D. G.; Yu, B.; Howe, J. Y.; Luo, H.; Dai, S.; Li, H.; Blau, P. J.; Bunting, B. G.; Mordukhovich, G.; et al. Antiwear Performance and Mechanism of an Oil-Miscible Ionic Liquid as a Lubricant Additive. ACS Appl. Mater. Interfaces 2012, 4 (2), 997.

(49) Yu, B.; Bansal, D. G.; Qu, J.; Sun, X.; Luo, H.; Dai, S.; Blau, P. J.; Bunting, B. G.; Mordukhovich, G.; Smolenski, D. J. Oil-Miscible and Non-Corrosive Phosphonium-Based Ionic Liquids as Candidate Lubricant Additives. Wear 2012, 289, 58.

(50) Barnhill, W. C.; Qu, J.; Luo, H.; Meyer, H. M.; Ma, C.; Chi, M.; Papke, B. L. Phosphonium-Organophosphate Ionic Liquids as Lubricant Additives: Effects of Cation Structure on Physicochemical and Tribological Characteristics. ACS Appl. Mater. Interfaces 2014, 6 (24), 22585.

(51) Qu, J.; Luo, H.; Chi, M.; Ma, C.; Blau, P. J.; Dai, S.; Viola, M. B. Comparison of an Oil-Miscible Ionic Liquid and ZDDP as a Lubricant Anti-Wear Additive. Tribol. Int. 2014, 71, 88.

(52) Fraser, K. J.; MacFarlane, D. R. Phosphonium-Based Ionic Liquids: An Overview. Aust. J. Chem. 2009, 62 (4), 309.

(53) Blahušiak, M.; Schlosser, Š. Physical Properties of Phosphonium Ionic Liquid and Its Mixtures with Dodecane and Water. J. Chem. Thermodyn. 2014, 72, 54.

(54) Pereiro, A. B.; Veiga, H. I. M.; Esperança, J. M. S. S.; Rodríguez, A. Effect of temperature on the physical properties of two ionic liquids. J. Chem. Thermodyn. 2009, 41, 1419-23.

(55) Cambiella, A.; Benito, J. M.; Pazos, C.; Coca, J.; Hernández, A.; Fernández, J. E. Formulation of Emulsifiable Cutting Fluids and Extreme Pressure Behaviour. J. Mater. Process. Technol. 2007, 184 (13), 139.

(56) Tadros, T. F.; Vincent, B. Liquid/Liquid Interfaces. Encyclopedia of Emulsion Technology; Marcel Dekker Inc.: New York, 1983; Vol. 1.

(57) Cabezas, M. G.; Bateni, A.; Montanero, J. M.; Neumann, A. W. Determination of Surface Tension and Contact Angle from the Shapes of Axisymmetric Fluid Interfaces without Use of Apex Coordinates. Langmuir 2006, 22 (24), 10053.

(58) Sun, C.-C.; Lee, S.-C.; Hwang, W.-C.; Hwang, J.-S.; Tang, I.-T.; Fu, Y.-S. Surface Free Energy of Alloy Nitride Coatings Deposited Using Closed Field Unbalanced Magnetron Sputter Ion Plating. Mater. Trans. 2006, 47 (10), 2533.

(59) Cwikel, D.; Zhao, Q.; Liu, C.; Su, X.; Marmur, A. Comparing Contact Angle Measurements and Surface Tension Assessments of Solid Surfaces. Langmuir 2010, 26 (19), 15289.

(60) Owens, D. K.; Wendt, R. C. Estimation of the Surface Free Energy of Polymers. J. Appl. Polym. Sci. 1969, 13, 1741. 